\title{
Serum heme oxygenase- 1 measurement is useful for evaluating disease activity and outcomes in patients with acute respiratory distress syndrome and acute exacerbation of interstitial lung disease
}

Ryo Nagasawa' ${ }^{1}$, Yu Hara ${ }^{1 *}$, Kota Murohashi ${ }^{1}$, Ayako Aoki ${ }^{1}$, Nobuaki Kobayashi', Shigeto Takagi²,

Satoru Hashimoto ${ }^{3}$, Akihiko Kawana ${ }^{4}$ and Takeshi Kaneko ${ }^{1}$

\begin{abstract}
Background: Oxidative stress plays an important role in acute lung injury, which is associated with the development and progression of acute respiratory failure. Here, we investigated whether the degree of oxidative stress as indicated by serum heme oxygenase-1 (HO-1) is clinically useful for predicting prognosis among the patients with acute respiratory distress syndrome (ARDS) and acute exacerbation of interstitial lung disease (AE-ILD).

Methods: Serum HO-1 levels of newly diagnosed or untreated ARDS and AE-ILD patients were measured at diagnosis. Relationships between serum HO-1 and other clinical parameters and 1 and 3-month mortality were evaluated.

Results: Fifty-five patients including 22 of ARDS and 33 of AE-ILD were assessed. Serum HO-1 level at diagnosis was significantly higher in ARDS patients than AE-ILD patients $(87.8 \pm 60.0 \mathrm{ng} / \mathrm{mL}$ vs. $52.5 \pm 36.3 \mathrm{ng} / \mathrm{mL}, P<0.001)$. Serum HO-1 correlated with serum total bilirubin $(R=0.454, P<0.001)$ and serum LDH $(R=0.500, P<0.001)$. In both patients with ARDS and AE-ILDs, serum HO-1 level tended to decrease from diagnosis to 2 weeks after diagnosis, however, did not normalized. Composite parameters including serum HO-1, age, sex, and partial pressure of oxygen in arterial blood/ fraction of inspired oxygen (P/F) ratio for prediction of 3-month mortality showed a higher AUC (ARDS: 0.925, AE-ILDs: 0.892) than did AUCs of a single predictor or combination of two or three predictors.
\end{abstract}

Conclusion: Oxidative stress assessed by serum HO-1 is persistently high among enrolled patients for 2 weeks after diagnosis. Also, serum HO-1 levels at the diagnosis combined with age, sex, and P/F ratio could be clinically useful for predicting 3-month mortality in both ARDS and AE-ILD patients.

Keywords: Acute respiratory distress syndrome, Heme oxygenase-1, Interstitial lung disease, Lung injury, Oxidative stress, Disease activity, Outcome

\footnotetext{
*Correspondence: yhara723@yokohama-cu.ac.jp

'Department of Pulmonology, Yokohama City University Graduate School of Medicine, 3-9 Fukuura, Kanazawa-ku, Yokohama City 236-0004, Japan

Full list of author information is available at the end of the article
}

(c) The Author(s). 2020 Open Access This article is licensed under a Creative Commons Attribution 4.0 International License, which permits use, sharing, adaptation, distribution and reproduction in any medium or format, as long as you give appropriate credit to the original author(s) and the source, provide a link to the Creative Commons licence, and indicate if changes were made. The images or other third party material in this article are included in the article's Creative Commons licence, unless indicated otherwise in a credit line to the material. If material is not included in the article's Creative Commons licence and your intended use is not permitted by statutory regulation or exceeds the permitted use, you will need to obtain permission directly from the copyright holder. To view a copy of this licence, visit http://creativecommons.org/licenses/by/4.0/. The Creative Commons Public Domain Dedication waiver (http://creativecommons.org/publicdomain/zero/1.0/) applies to the data made available in this article, unless otherwise stated in a credit line to the data. 


\section{Introduction}

Acute respiratory distress syndrome (ARDS) is one of the major manifestations of multiple organ failure syndrome and is a leading cause of death in intensive care units [1]. Within the clinical course of interstitial lung disease (ILD), an acute exacerbation (AE) can occur at any time and is associated with significant morbidity and mortality [2]. Diffuse alveolar damage (DAD) is considered the histological hallmark of the acute phase of ARDS and AEILDs, while alternative histological appearances comprise organizing pneumonia, alveolar haemorrhage, and unspecific inflammatory changes $[3,4]$. The clinical course and rate of progression of ARDS and AE-ILDs are extremely variable among patients. Therefore, biomarkers including symptoms, blood, physiological, radiological, and pathological findings and these combinations may be useful in characterizing disease severity and predicting the rate of progression and response to therapies $[5,6]$.

Oxidative/nitrosative stress results from an imbalance between cellular production of reactive oxygen species (ROS)/ reactive nitrogen species (RNS) and the endogenous antioxidants such as stress response protein (heme oxygenase-1 (HO-1)), classic antioxidant enzymes (superoxide dismutases (SODs), catalase, glutathione peroxidase (GPx)) [7]. Nuclear factor-erythroid 2 p45 subunit-related factor 2 (Nrf2) is essential for activating response in the lung due to induction of the expression of antioxidant and these enzymes are expressed in bronchial and alveolar epithelial cells and macrophages of the lung [8]. Several clinical evidences suggested that increased oxidative/nitrosative stress might play a major role in the progression of various lung diseases such as idiopathic pulmonary fibrosis (IPF), chronic obstructive pulmonary disease, and ARDS [9-14]. HO-1 catalyzes heme degradation to biliverdin-IX $\alpha$, carbon monoxide, and iron. These metabolites mediate the antiapoptotic, anti-inflammatory, vasodilatory, anticoagulant, antioxidant, and antiproliferative properties of $\mathrm{HO}-1$ under the control of the microsomal nicotinamide adenine dinucleotide phosphate-cytochrome p450 reductase $[15,16]$. HO-1 expression is induced by various stimuli such as exposure of cigarette smoke extract (CSE), heme, hypoxia, endotoxin, and pro-inflammatory cytokines. Suzuki et al. reported that in human alveolar macrophages, acute CSE exposure increases HO-1 mRNA for $2 \mathrm{~h}$ [17]. Mumby et al. reported that $\mathrm{HO}-1$ protein concentrations are significantly elevated in lung tissue and bronchoalveolar lavage fluid taken from ARDS patients compared with controls, and HO-1 expression contributes to changes in iron mobilization, signalling, and regulation seen in this condition [18]. Also, we have demonstrated the usefulness of measuring serum HO-1 in the diagnosis and prognosis of patients with ARDS and AE-ILDs [19, 20]. Therefore, we speculate that $\mathrm{HO}-1$ characterized as rapid stress response protein with various physiological activities caused by $\mathrm{HO}$ -
1 metabolites could reflect pulmonary cellular damage induced by ROS and RNS more closely and directly [7, 1517].

In the present study, we investigated whether the degree of oxidative stress measured by serum HO-1 levels at the diagnosis could be useful for predicting prognosis and these levels could decrease during the clinical courses among patients with ARDS and AE-ILDs.

\section{Methods \\ Study location and diagnosis of ARDS asnd AE-ILDs}

This multi-institutional prospective study was performed in Yokohama City University, Kyoto Prefectural University, and National Defense Medical College Hospital between 2011 and 2019. We recruited untreated ARDS patients who met the Berlin definition [21]. The diagnosis of idiopathic interstitial pneumonias (IIPs) was confirmed by physical findings, serological testing, high resolution CT (HRCT) finding, and lung biopsy specimens, based on the official statement for IIPs including IPF [22, 23]. Patients whose lung biopsy could not be performed due to severe respiratory failure were diagnosed based on the radiological classification [22, 23]. The diagnosis of collagen vascular disease-related interstitial pneumonia (CVD-IP) was confirmed by physical findings, serological testing, and HRCT findings that were consistent with ILD. AE-ILD patients were defined as having unexplained worsening of dyspnoea; hypoxaemia or worsening or severely impaired gas exchange; new alveolar infiltrates superimposed upon chronic ILD lesions on radiograph; and absence of an alternative explanation such as infection, pulmonary embolism, pneumothorax, or heart failure $[24,25]$. In addition, we recruited healthy volunteers among medical personnel of Seamen's Insurance Health Management Center for health examination.

\section{Data collection and blood sampling}

Extracted data included age, sex, diagnosis including the causes of ARDS, and 1 and 3-month mortality. Blood samples were obtained at the diagnosis of ARDS or AE-ILD from each patient. We measured serum HO-1 along with serum total bilirubin (T-bil; normal range: $0.2-1.2 \mathrm{mg} / \mathrm{dL}$ ), serum lactate dehydrogenase (LDH; normal range: < $225 \mathrm{U} /$ $\mathrm{L})$, serum C-reactive protein (CRP; normal range: $\leq 0.3 \mathrm{mg} /$ $\mathrm{dL}$ ), and partial pressure of oxygen in arterial blood/fraction of inspired oxygen $(\mathrm{P} / \mathrm{F})$ ratio.

Serum HO-1 enzyme-linked immunosorbent assay (ELISA) measurement

Serum HO-1 levels were measured at the time of ARDS or AE-ILD diagnosis (D0) and 7 (D7) and 14 (D14) days from the diagnosis using the IMMUNOSET ${ }^{\oplus} \mathrm{HO}-1$ (human) ELISA development set (Enzo, Farmingdale, NY, USA), according to the manufacturer's instructions. The 
details of this ELISA method have been described previously [19]. The assay validation was performed reproducibility of ELISA standard curve for serum HO-1, the intra- and inter-assay tests, and the percentage recovery test. We confirmed all of these results were acceptable [19]. Control subjects for serum HO-1 levels included 28 healthy, non-smoking adults who had been admitted to the hospital for a medical checkup.

\section{Statistical analysis}

Data are expressed as mean \pm standard deviation. Statistical analysis was performed using JMP11 (SAS Institute, Inc., North Carolina, USA). Group comparisons were made using Wilcoxon's rank-sum test or the chi-squared test, as appropriate. Spearman's correlation coefficients were calculated to assess the relationship between serum
HO-1 and other clinical parameters. The applicability of serum HO-1 with or without other clinical parameters in predicting 3-month mortality was evaluated using the area under a receiver operating characteristic (ROC) curve (AUC). Survival curves were generated using the KaplanMeier method and were compared using the Wilcoxon test. $P$ values $<0.05$ were considered significant.

\section{Results}

\section{Patients' characteristics}

Table 1 shows the clinical characteristics of patients with ARDS and AE-ILDs. Among the 55 enrolled patients, 22 were diagnosed with ARDS and 33 were diagnosed with AE-ILDs. The causes of ARDS included infection $(n=$ $14,60 \%)$ and surgery $(n=5,23 \%)$. The diagnosis of ILDs including IIPs $(n=21,64 \%)$ and CVD-IP $(n=8,24 \%)$

Table 1 Patients' characteristics

\begin{tabular}{|c|c|c|c|c|}
\hline Characteristics & $\begin{array}{l}\text { ARDS patients } \\
(n=22)\end{array}$ & $\begin{array}{l}\text { AE-ILD patients } \\
(n=33)\end{array}$ & $\begin{array}{l}\text { Total patients } \\
(n=55)\end{array}$ & $\begin{array}{l}\text { P values } \\
\text { (ARDS vs. AE-ILDs) }\end{array}$ \\
\hline Age, y & $66.5 \pm 10.2$ & $75.0 \pm 8.0$ & $71.4 \pm 9.9$ & 0.003 \\
\hline Male sex & $16(73)$ & $21(72)$ & $37(73)$ & 0.980 \\
\hline \multicolumn{5}{|l|}{ Aetiology of ARDS } \\
\hline Infection & $14(60)$ & & $14(60)$ & \\
\hline Surgery & $5(23)$ & & $5(23)$ & \\
\hline Others & $3(17)$ & & $3(17)$ & \\
\hline \multicolumn{5}{|l|}{ Diagnosis of ILDs } \\
\hline$\| I P s^{a}$ & & $21(64)$ & $21(64)$ & \\
\hline CVD-IP & & $8(24)$ & $8(24)$ & \\
\hline Others & & $4(12)$ & $4(12)$ & \\
\hline \multicolumn{5}{|l|}{ Blood biomarkers } \\
\hline $\mathrm{P} / \mathrm{F}$ ratio & $186.7 \pm 103.7$ & $219.4 \pm 73.8$ & $204.4 \pm 89.3$ & 0.094 \\
\hline Serum LDH, U/L & $368.5 \pm 223.0$ & $332.7 \pm 20.9$ & $347.0 \pm 168.9$ & 0.993 \\
\hline Serum HO-1, ng/mL & $87.8 \pm 60.0$ & $52.5 \pm 36.3$ & $66.6 \pm 49.9$ & 0.011 \\
\hline Serum total bilirubin, $\mathrm{mg} / \mathrm{dL}$ & $3.9 \pm 7.5$ & $0.9 \pm 0.4$ & $2.1 \pm 5.0$ & 0.090 \\
\hline Serum CRP, mg/dL & $16.6 \pm 10.8$ & $9.4 \pm 6.9$ & $12.3 \pm 9.3$ & 0.008 \\
\hline \multicolumn{5}{|l|}{ Treatment } \\
\hline Corticosteroid use & $13(59)$ & $33(100)$ & $46(82)$ & $<0.001$ \\
\hline Corticosteroid pulse use & $3(14)$ & $27(82)$ & $30(55)$ & $<0.001$ \\
\hline Frequency of PSL pulse & 1 & $1(1-4)$ & $1(1-4)$ & 0.304 \\
\hline NEI use & $15(68)$ & $11(33)$ & $26(47)$ & 0.011 \\
\hline Intubation & $22(100)$ & $0(0)$ & $22(40)$ & $<0.001$ \\
\hline \multicolumn{5}{|l|}{ Outcome } \\
\hline 1-month mortality & $10(45)$ & $3(9)$ & $13(24)$ & $<0.001$ \\
\hline 3-month mortality & $10(45)$ & $8(24)$ & $18(33)$ & 0.015 \\
\hline
\end{tabular}

Footnotes

Values are reported as mean \pm SD or $\mathrm{n}(\%)$

aIIPs consisted of 11 patients with idiopathic pulmonary fibrosis patients and 10 patients with non-specific interstitial pneumonia

Abbreviations: $A E$ acute exacerbation, ARDS acute respiratory distress syndrome, CRP C-reactive protein, CVD-IP collagen vascular disease-related interstitial pneumonia, HO-1 heme oxygenase-1, IIPs idiopathic interstitial pneumonias, ILDs interstitial lung diseases, $L D H$ lactate dehydrogenase, NEI neutrophil elastase inhibitor, $P / F$ ratio partial pressure of oxygen in arterial blood/fraction of inspired oxygen, $S D$ standard deviation 
A

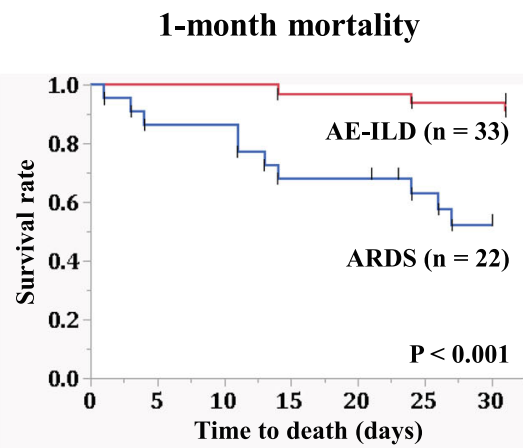

B

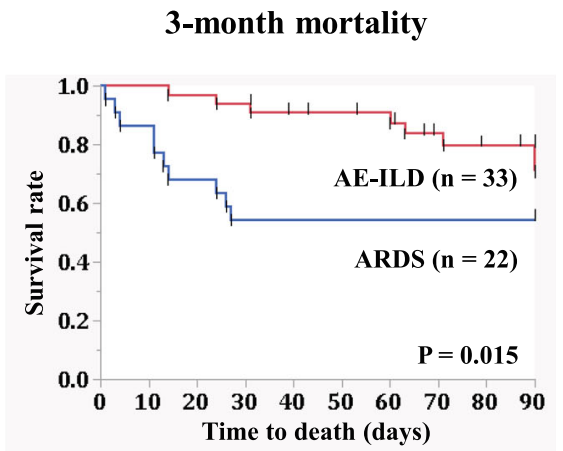

Fig. 1 Comparison of 1- and 3-month mortality between ARDS and AE-ILD patients. Among the 55 enrolled patients, 22 were diagnosed with ARDS, and 33 were diagnosed with AE-ILDs. A significant difference in the 1-month mortality rate was evident between ARDS and AE-ILD patients ( $45 \%$ vs. $9 \%$, respectively, $P<0.001)$. Also, a significant difference in the 3 -month mortality rate was observed $(45 \%$ vs. $24 \%$, respectively, $\mathrm{P}=0.015)$

was previously confirmed before the onset of AE. IIPs consisted of 11 patients with IPF patients and 10 patients with non-specific interstitial pneumonia. Among blood biomarkers, serum HO-1 and CRP levels were higher in ARDS patients than in AE-ILD patients $(P<0.05)$. Serum HO-1 in both ARDS and AE-ILD patients were higher than control subjects $(9.5 \pm 3.3 \mathrm{ng} / \mathrm{mL}$ $(n=44))$. As shown in Fig. 1a, a significant difference in the 1-month mortality rate was evident between ARDS and AE-ILD patients $(45 \%$ vs. $9 \%$, respectively, $P<0.001$ ). Also, as shown in Fig. 1b, a significant difference in the 3-month mortality rate was observed among these patients ( $45 \%$ vs. $24 \%$, respectively, $P=0.015$ ).

\section{Serum HO-1 at the baseline (DO) and other blood biomarkers}

Serum HO-1 levels were significantly higher in ARDS patients than in AE-ILD patients at D0 $(87.8 \pm 60.0 \mathrm{ng} / \mathrm{mL}$ vs. $52.5 \pm 36.3 \mathrm{ng} / \mathrm{mL}$, respectively, $\mathrm{P}<0.001)$. As shown in Table 2, serum HO-1 significantly correlated with serum $\mathrm{T}$-bil $(\mathrm{R}=0.454, \mathrm{P}<0.001)$ and $\mathrm{LDH}(\mathrm{R}=0.500$, $\mathrm{P}<0.001)$, but not with serum CRP and $\mathrm{P} / \mathrm{F}$ ratio.

\section{Variation in serum HO-1 levels (D0, D7, and D14)}

Serum HO-1 levels at D0, D7, and D14 were available in 35 of 55 patients $(64 \%)$. Of these 35 patients, 18 (51\%) patients had ARDS and 17 (49\%) patients had AE-ILDs. As shown in Fig. 2a (all patients), serum HO-1 levels tended to decrease over time, and serum HO-1 levels at D14 were significantly lower than those at D0 (81.1 \pm $9.3 \mathrm{ng} / \mathrm{mL}$ vs. $60.9 \pm 52.4 \mathrm{ng} / \mathrm{mL}$, respectively, $P=0.016$ ). As shown in Fig. 2b, significant differences were observed between serum HO-1 levels at D0 and D14 in the ARDS patients $(95.7 \pm 61.6 \mathrm{ng} / \mathrm{mL}$ vs. $67.8 \pm 61.3 \mathrm{ng} / \mathrm{mL}$, respectively, $P=0.041$ ). Although serum $\mathrm{HO}-1$ levels in the AE-ILD patients tended to decrease over time, no significant differences were observed between timepoints (Fig. 2c). Also, we evaluated the variation in serum HO1 levels in patients treated with corticosteroid. As shown in Fig. 2d, 28 patients (51\%) were treated with corticosteroid and had available serum HO-1 levels at D0, D7, and D14. No significant difference was observed between serum HO-1 levels at D0, D7, and D14 $(77.1 \pm 56.3 \mathrm{ng} /$ $\mathrm{mL} \quad$ vs. $\quad 78.4 \pm 66.0 \mathrm{ng} / \mathrm{mL} \quad$ vs. $\quad 64.7 \pm 57.8 \mathrm{ng} / \mathrm{mL}$, respectively).

\section{Composite parameters for predicting 3-month mortality in patients with ARDS and AE-ILDs}

In both patients with ARDS and AE-ILDs, we evaluated the predictability for the 3-month mortality. In patients with ARDS, composite parameters including serum HO$1, \mathrm{P} / \mathrm{F}$ ratio, age and sex for prediction of 3-month mortality showed a higher AUC (0.925) than AUCs of a single predictor (only HO-1; 0.783) or combination of two (HO-1 and age; 0.783 ) or three predictors (HO-1, age, and sex; 0.917) (Fig. 3a). Furthermore, composite parameters including serum $\mathrm{HO}-1, \mathrm{P} / \mathrm{F}$ ratio, age and sex showed a higher AUC (0.925) than AUC of the acute physiology and chronic health evaluation (APACHE) II score which was frequently used to measure disease severity in intensive care unit patients with ARDS (AUC;

Table 2 Relationships between serum $\mathrm{HO}-1$ and other blood parameters

\begin{tabular}{lllll}
\hline Variables & $\mathbf{N}$ & $\mathbf{R}$ & $\mathbf{9 5 \%} \mathbf{C l}$ & $\mathbf{P}$ \\
\hline Serum T-bil & 54 & 0.454 & $0.212-0.644$ & $<0.001$ \\
Serum LDH & 55 & 0.500 & $0.271-0.676$ & $<0.001$ \\
Serum CRP & 55 & 0.262 & $-0.004-0.493$ & 0.053 \\
P/F ratio & 48 & -0.159 & $-0.424-0.131$ & 0.281 \\
\hline
\end{tabular}

$\mathrm{Cl}$ confidence interval, $C R P$ C-reactive protein, $\mathrm{HO}-1$ heme oxygenase-1, $\mathrm{LDH}$ lactate dehydrogenase, $P / F$ ratio partial pressure of oxygen in arterial blood/ fraction of the inspiratory oxygen; T-bil, total bilirubin 


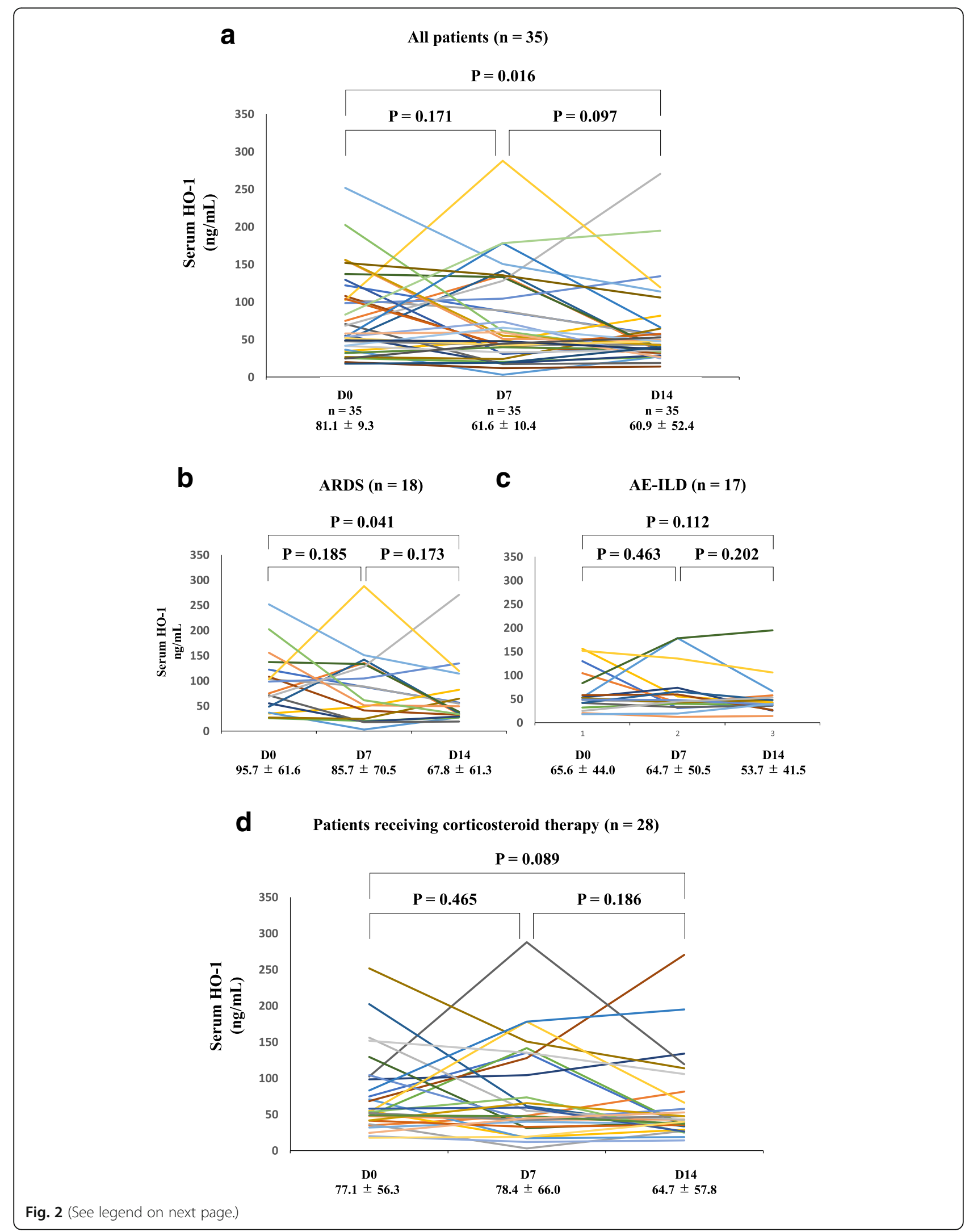


(See figure on previous page.)

Fig. 2 Variation in serum HO-1 levels at the time of diagnosis (D0) and 7 (D7) and 14 (D14) days from the diagnosis. Serum HO-1 levels were measured at the time of ARDS or AE-ILD diagnosis (D0) and 7 (D7) and 14 (D14) days from the diagnosis. Serum HO-1 levels at D0, D7, and D14 were available in 35 of 55 patients (64\%). Of the 35 patients, 18 (51\%) had ARDS and 17 (49\%) had AE-ILDs. As shown in a (all patients), serum HO-1 at D0, D7, and D14 tended to decrease, and serum HO-1 levels at D14 were significantly decreased compared with those at D0 (81.1 \pm 9.3 $\mathrm{ng} / \mathrm{mL}$ vs. $60.9 \pm 52.4 \mathrm{ng} / \mathrm{mL}$, respectively, $\mathrm{P}=0.016)$. Furthermore, as shown in $\mathbf{b}$, significant differences were observed between serum HO-1 levels at D0 and D14 in the ARDS group $(95.7 \pm 61.6 \mathrm{ng} / \mathrm{mL}$ vs. $67.8 \pm 61.3 \mathrm{ng} / \mathrm{mL}$, respectively, $P=0.041)$. As shown in c, while serum HO-1 levels of the AE-ILD group tended to decrease, these differences were not significant. As shown in $\mathbf{d}, 28$ (51\%) were treated with corticosteroid and had available HO-1 levels at the time of D0 and D7 and D14 and no significant difference was observed between serum HO-1 levels at D0, D7, and D14 (77.1 $\pm 56.3 \mathrm{ng} / \mathrm{mL}$ vs. $78.4 \pm 66.0 \mathrm{ng} / \mathrm{mL}$ vs. $64.7 \pm 57.8 \mathrm{ng} / \mathrm{mL}$, respectively)

0.563) [26]. In patients with AE-ILDs, composite parameters including serum HO-1, $\mathrm{P} / \mathrm{F}$ ratio, age and sex for prediction of 3-month mortality showed a higher AUC (0.892) than AUCs of a single predictor (only HO-1; 0.685 ) or combination of two (HO-1 and age; 0.708$)$ or three predictors (HO-1, age, and sex; 0.714) (Fig. 3b).

\section{Discussion}

Increased oxidative/nitrosative stress might play a major role in the progression of various lung diseases including AE-ILDs and ARDS [9-14]. HO-1, a rate-limiting enzyme in heme catabolism, has antioxidative activities in patients with these diseases [27-29]. We previously investigated whether evaluating the degree of oxidative stress by measuring serum HO-1 using the sandwich ELISA method is useful for assessing disease activities and predicting prognosis in patients with ARDS and AEILDs $[19,20]$. In the present study which was an integrated analysis of these previous studies, we investigated whether composite parameters including serum HO-1 and other clinical parameters could predict the prognosis of ARDS and AE-ILDs more accurately than serum HO-1 alone and oxidative stress measured by serum HO-1 levels could be reduced in the clinical course.

ARDS and AE-ILDs are a life-threatening event and the mortality rate is high [30, 31]. A retrospective analysis in patients with ARDS showed a significant increase in hospital mortality in patients with DAD compared to those without DAD (71.9\% vs. $45.5 \%)$ [30]. Other retrospective cohort study in patients with $\mathrm{AE}$ of chronic fibrosing IP showed the overall survival after admission was $67 \%$ at 1 month and $40 \%$ at 3 months [31]. In both patients with ARDS and AE-ILDs, our data showed better prognosis than these cohort studies, however, the patients with ARDS tended to show worse prognosis than those with AE-ILDs as previously reported. In the present study, ARDS patients had significantly higher serum HO-1 and CRP levels at baseline compared with AE-ILD patients and serum HO-1 had positive correlation with serum LDH. These results indicate that ARDS patients had a stronger degree of systemic inflammatory response, pulmonary epithelial cell damage and endothelial cell damage with the consequent increase of vascular permeability reflecting oxidative/nitrosative stress response than AE-ILD patients [32-34]. Though similar with HO-1, SODs, catalase, and GPx had been described as the endogenous antioxidants, $\mathrm{HO}-1$ characterized as stress response protein with relatively small-molecular weight $(32 \mathrm{kDa}$, much smaller than KL-6 (5000 kDa)), rapid response against stimuli, and various physiological activities including the antiapoptotic, anti-inflammatory, vasodilatory, anticoagulant, antioxidant, and antiproliferative reactions caused by HO-1 metabolites [7, 15-17]. Therefore, we speculate that serum HO-1 reflects pulmonary cellular damage induced by ROS and RNS more closely and directly.

Ongoing and persistent oxidative stress leads to poor prognosis [35]. In patients with ILDs, persistently high ethane levels, a product of lipid peroxidation that has been proposed as a biomarker of oxidative stress, may correlate with poor prognosis [35]. Cancer cells with persistent Nrf2 activation often develop Nrf2 addiction and show malignant phenotypes, leading to poor prognoses [36]. In the present study, although serum HO-1 levels tended to decrease 2 weeks after the start of treatment in both ARDS and AE-ILD patients, serum HO-1 levels remained persistently high. Furthermore, in patients treated with intravenous corticosteroids, no significant decrease of serum HO-1 levels was observed. Systemic corticosteroids are able to block nuclear translocation of nuclear factor- $k B$, the main pathway of inflammatory cytokine synthesis, through their interaction with the glucocorticoid receptor, however, the use of corticosteroid in ARDS is not recommended routinely [37, 38]. Also, retrospective data derived from AE-IPF patients treated with corticosteroid alone did not show any reduction in mortality rate over the short term [39]. Several evidence in the animal models suggest that corticosteroid exposure can cause to increase oxidative stress $[40,41]$. Although the exact mechanism by which corticosteroid increase oxidative stress is not well known, several hypothesis have been reported that glucocorticoids could bind to mitochondrial glucocorticoid receptors and activate mitochondrial function to generate ROS or ROS is generated by the activation of the protein kinase $C$ (PKC) $\beta /$ p66 ${ }^{\text {shc }}$ signaling pathway by glucocorticoid in the cell $[40,41]$. Therefore, in patients with ARDS and AE-ILDs, the use of corticosteroids 
a

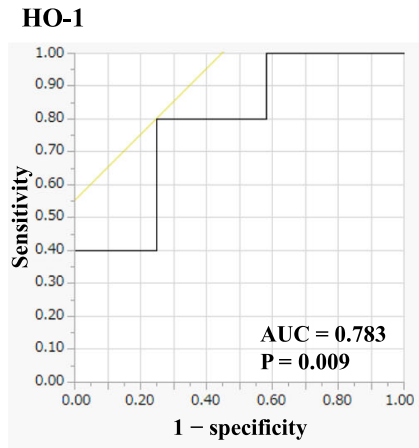

HO-1 + age + sex

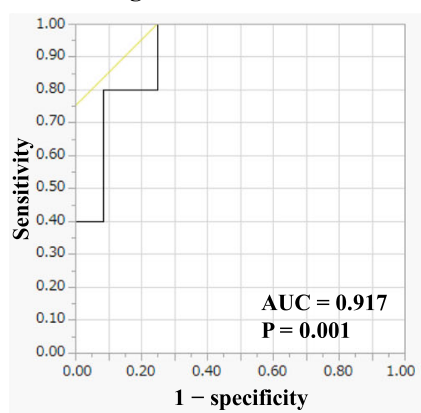

b

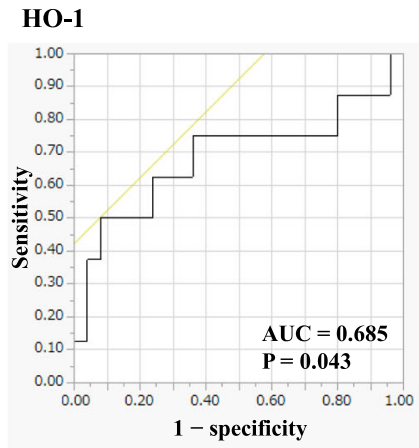

HO-1 + age + sex

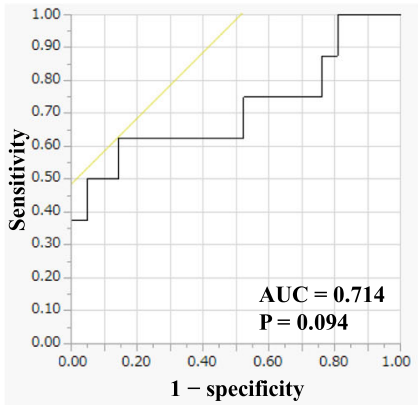

HO-1 + age

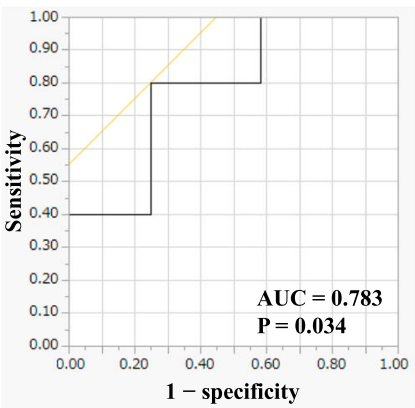

HO-1 + age + sex + P/F ratio
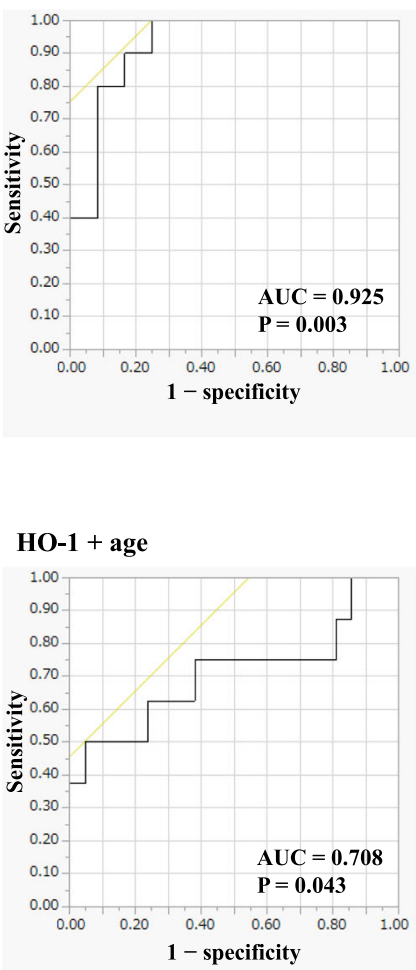

HO-1 + age + sex + P/F ratio

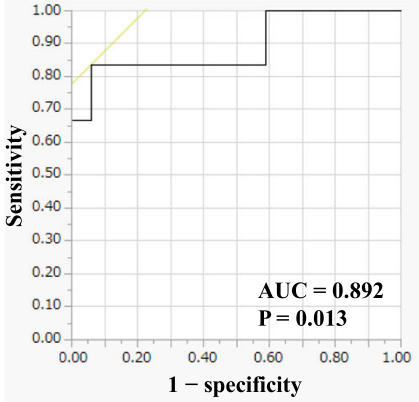

Fig. 3 (See legend on next page.) 
(See figure on previous page.)

Fig. 3 Composite parameters for predicting 3-month mortality in patients with ARDS and AE-ILDs. In both patients with ARDS and AE-ILDs, we evaluated the predictability for the 3-month mortality. In patients with ARDS, composite parameters including serum HO-1, P/F ratio, age and sex for prediction of 3-month mortality showed a higher AUC (0.925) than AUCs of a single predictor (only HO-1; 0.783) or combination of two (HO-1 and age; 0.783 ) or three predictors ( $\mathrm{HO}-1$, age, and sex; 0.917) (a). Also, in patients with AE-ILDs, composite parameters including serum $\mathrm{HO}-1, \mathrm{P} / \mathrm{F}$ ratio, age and sex for prediction of 3-month mortality showed a higher AUC (0.892) than AUCs of a single predictor (only HO-1; 0.685) or combination of two (HO-1 and age; 0.708) or three predictors (HO-1, age, and sex; 0.714) (b)

may be harmful from the point of view of oxidative stress increase, and the potential antioxidant treatment such as $\mathrm{N}$-acetylcysteine needs to be examined in the future [42].

Composite approaches have been developed using peripheral blood biomarkers and physiological and radiographic measurements to provide more accurate prognostic information [26, 43, 44]. For example, APACHE II score is frequently used to measure disease severity in intensive care unit patients with ARDS [26]. The composite scoring system, which is based on serum LDH, Krebs von den Lungen-6, P/F ratio, and extent of abnormal high resolution computed tomography findings, is useful for predicting 3month mortality in AE-IPF patients [43]. We previously demonstrated that the Charlson Comorbidity Index score, sex, and serum LDH are important for predicting 3-month mortality in AE-ILD patients [44]. In the present study, we found that composite parameters including serum $\mathrm{HO}-1, \mathrm{P} / \mathrm{F}$ ratio, sex, and age which was characterised as objective biomarkers had acceptable AUC for prediction of 3-month mortality in ARDS and AE-ILD patients. Our data suggest that composite parameters including serum $\mathrm{HO}-1$ and other clinical parameters could predict the prognosis of ARDS and AE-ILDs more accurately than serum HO-1 alone. To verify the utility and reproducibility of this composite parameters, large-scale, multiinstitutional prospective collaborative research is essential.

There are several limitations to the present study. First, the study enrolled only a small number of patients from a few institutions. Our findings need to be confirmed in a multi-centre, prospective study. Second, the various endogenous oxidative stress markers such as not only HO-1 but also SODs, catalase, GPx, and myeloperoxidase have been reported. It is necessary to evaluate which markers are the most reliable for predicting the prognosis of ARDS and AE-ILDs. Third, clinical diagnoses among ARDS and AE-ILD patients were heterogeneous. Actually, in both patients with ARDS and AEILDs, our data showed better prognosis than the previously reported cohort data. In the future, it is necessary to evaluate the clinical significance of serum $\mathrm{HO}-1$ in patients with DAD histologically.

\section{Conclusions}

Oxidative stress assessed by serum HO-1 is persistently high among enrolled patients for 2 weeks after diagnosis despite treatment with corticosteroids. Also, composite parameters including serum $\mathrm{HO}-1, \mathrm{P} / \mathrm{F}$ ratio, sex, and age had acceptable AUCs for prediction of 3-month mortality in ARDS and AE-ILD patients.

\section{Abbreviations \\ AE: Acute exacerbation; APACHE: Acute physiology and chronic health evaluation; ARDS: Acute respiratory distress syndrome; AUC: Area under the ROC curve; CRP: C-reactive protein; CSE: Cigarette smoke extract; CVD- IP: Collagen vascular disease-related interstitial pneumonia; DAD: Diffuse alveolar damage; ELISA: Enzyme-linked immunosorbent assay; \\ GPx: Glutathione peroxidase; HO-1: Heme oxygenase-1; HRCT: High resolution CT; IIPs: Idiopathic interstitial pneumonias; ILD: Interstitial lung disease; IPF: Idiopathic pulmonary fibrosis; LDH: Lactate dehydrogenase; Nrf2: Nuclear factor erythroid 2-related factor 2; P/F ratio: Partial pressure of oxygen in arterial blood/fraction of inspired oxygen; PKC: Protein kinase C; RNS: Reactive nitrogen species; ROC: Receiver operating characteristic; ROS: Reactive oxygen species; SODs: Superoxide dismutases; T-bil: Total bilirubin}

\section{Acknowledgements}

We thank Ms. Aya Yabe for measuring serum HO-1. This research was supported by the Yokohama City University Research Fund.

\section{Authors' contributions}

NR and HY were responsible for study conception, design, data analysis, and drafting manuscript; $\mathrm{HY}$ and $\mathrm{MK}$ were responsible for acquisition of data; MK, $A A, K N, T S, H S, K A$, and $K T$ were responsible for drafting and revision of the manuscript. All authors have read and approved the manuscript.

\section{Funding}

The authors declare that they are not funded by any funding body.

\section{Availability of data and materials}

The datasets used and/or analysed during the current study are available from the corresponding author on reasonable request.

\section{Ethics approval and consent to participate}

All aspects of this research were approved by the Institutional Review Board of Yokohama City University Graduate School of Medicine (approval numbers B170900025 and A181100007). The severely ill condition or deep sedation of ARDS and AE-ILD patients precluded us from obtaining informed consent from the patients themselves. Therefore, written informed consent was obtained from the patients' relatives or their legal guardians. Control subjects provided written informed consent prior to participation in this study.

\section{Consent for publication}

Written consent for publication from the patients or their next of kin was obtained.

\section{Competing interests}

The authors declare that they have no competing interests. 


\section{Author details}

${ }^{1}$ Department of Pulmonology, Yokohama City University Graduate School of Medicine, 3-9 Fukuura, Kanazawa-ku, Yokohama City 236-0004, Japan. ${ }^{2}$ Seamen's Insurance Health Management Center, Yokohama, Japan. ${ }^{3}$ Division of Intensive Care Unit, Kyoto Prefectural University of Medicine, Kyoto, Japan. ${ }^{4}$ Division of Infectious Diseases and Pulmonary Medicine, Department of Internal Medicine, National Defense Medical College, Saitama, Japan.

Received: 2 July 2020 Accepted: 9 November 2020

Published online: 25 November 2020

\section{References}

1. Mayr VD, Dünser MW, Greil V, Jochberger S, Luckner G, Ulmer H, Friesenecker BE, Takala J, Hasibeder WR. Causes of death and determinants of outcome in critically ill patients. Crit Care. 2006;10:R154.

2. Song JW, Hong SB, Lim CM, Koh Y, Kim DS. Acute exacerbation of idiopathic pulmonary fibrosis: incidence, risk factors and outcome. Eur Respir J. 2011;37:356-63

3. Cardinal-Fernández P, Lorente JA, Ballén-Barragán A, Matute-Bello G. Acute respiratory distress syndrome and diffuse alveolar damage. New insights on a complex relationship. Ann Am Thorac Soc. 2017;14:844-50.

4. Churg A, Müller NL, Silva Cl, Wright JL. Acute exacerbation (acute lung injury of unknown cause) in UIP and other forms of fibrotic interstitial pneumonias. Am J Surg Pathol. 2007;31:277-84.

5. Raghu G, Collard HR, Egan JJ, Martinez FJ, Behr J, Brown KK, Colby TV, Cordier JF, Flaherty KR, Lasky JA, Lynch DA, Ryu JH, Swigris JJ, Wells AU, Ancochea J, Bouros D, Carvalho C, Costabel U, Ebina M, Hansell DM, Johkoh T, Kim DS, King TE Jr, Kondoh Y, Myers J, Müller NL, Nicholson AG, Richeldi L, Selman M, Dudden RF, Griss BS, Protzko SL, Schünemann HJ. ATS/ERS/ JRS/ALAT Committee on Idiopathic Pulmonary Fibrosis. An official ATS/ERS/ JRS/ALAT statement: idiopathic pulmonary fibrosis: evidence-based guidelines for diagnosis and management. Am J Respir Crit Care Med. 2011; 183:788-824.

6. Spadaro S, Park M, Turrini C, Tunstall T, Thwaites R, Mauri T, Ragazzi R, Ruggeri $P$, Hansel TT, Caramori G, Volta CA. Biomarkers for acute respiratory distress syndrome and prospects for personalised medicine. J Inflamm (Lond). 2019;16:1.

7. Hosseinzadeh A, Javad-Moosavi SA, Reiter RJ, Yarahmadi R, Ghaznavi H, Mehrzadi S. Oxidative/nitrosative stress, autophagy and apoptosis as therapeutic targets of melatonin in idiopathic pulmonary fibrosis. Expert Opin Ther Targets. 2018;22:1049-61.

8. Kinnula VL, Fattman CL, Tan RJ, Oury TD. Oxidative stress in pulmonary fibrosis: a possible role for redox modulatory therapy. Am J Respir Crit Care Med. 2005;172:417-22.

9. Cameli P, Carleo A, Bergantini L, Landi C, Prasse A, Bargagli E. Oxidant/ antioxidant disequilibrium in idiopathic pulmonary fibrosis pathogenesis. Inflammation. 2020;43:1-7.

10. Cameli P, Bergantini L, Salvini M, et al. Alveolar concentration of nitric oxide as a prognostic biomarker in idiopathic pulmonary fibrosis. Nitric Oxide. 2019;89:41-5.

11. de Groot LES, van der Veen TA, Martinez FO, Hamann J, Lutter R, Melgert BN. Oxidative stress and macrophages: driving forces behind exacerbations of asthma and chronic obstructive pulmonary disease? Am J Physiol Lung Cell Mol Physiol. 2019;316:L369-84.

12. Lenz AG, Jorens PG, Meyer B, De Backer W, Van Overveld F, Bossaert $L$, Maier KL. Oxidatively modified proteins in bronchoalveolar lavage fluid of patients with ARDS and patients at-risk for ARDS. Eur Respir J. 1999; 13:169-74.

13. Bargagli E, Olivieri C, Bennett D, Prasse A, Muller-Quernheim J, Rottoli P. Oxidative stress in the pathogenesis of diffuse lung diseases: a review. Respir Med. 2009;103:1245-56.

14. Hecker L. Mechanisms and consequences of oxidative stress in lung disease: therapeutic implications for an aging populace. Am J Physiol Lung Cell Mol Physiol. 2018;314:L642-53.

15. Fredenburgh LE, Perrella MA, Mitsialis SA. The role of heme oxygenase-1 in pulmonary disease. Am J Respir Cell Mol Biol. 2007;36:158-65.

16. Kikuchi G, Yoshida T, Noguchi M. Heme oxygenase and heme degradation. Biochem Biophys Res Commun. 2005;338:558-67.

17. Suzuki M, Betsuyaku T, Ito Y, Nagai K, Nasuhara Y, Kaga K, Kondo S, Nishimura M. Down-regulated NF-E2-related factor 2 in pulmonary macrophages of aged smokers and patients with chronic obstructive pulmonary disease. Am J Respir Cell Mol Biol. 2008;39:673-82.

18. Mumby S, Upton RL, Chen Y, Stanford SJ, Quinlan GJ, Nicholson AG, Gutteridge JM, Lamb NJ, Evans TW. Lung heme oxygenase-1 is elevated in acute respiratory distress syndrome. Crit Care Med. 2004;32:1130-5.

19. Hara $Y$, Shinkai M, Taguri M, Nagai K, Hashimoto S, Kaneko T. ELISA development for serum hemeoxygenase-1 and its application to patients with acute respiratory distress syndrome. Can Respir J. 2018;2018:9627420.

20. Murohashi K, Hara Y, Shinada K, Nagai K, Shinkai M, Kawana A, Kaneko T. Clinical significance of serum hemeoxygenase-1 as a new biomarker for the patients with interstitial pneumonia. Can Respir J. 2018;2018:7260178.

21. Definition Task Force ARDS, Ranieri VM, Rubenfeld GD, Thompson BT, Ferguson ND, Caldwell E, Fan E, Camporota L, Slutsky AS. Acute respiratory distress syndrome: the Berlin Definition. JAMA. 2012;307:2526-33.

22. Travis WD, Costabel U, Hansell DM, King TE Jr, Lynch DA, Nicholson AG, Ryerson CJ, Ryu JH, Selman M, Wells AU, Behr J, Bouros D, Brown KK, Colby TV, Collard HR, Cordeiro CR, Cottin V, Crestani B, Drent M, Dudden RF, Egan J, Flaherty K, Hogaboam C, Inoue Y, Johkoh T, Kim DS, Kitaichi M, Loyd J, Martinez FJ, Myers J, Protzko S, Raghu G, Richeldi L, Sverzellati N, Swigris J, Valeyre D, ATS/ERS Committee on Idiopathic Interstitial Pneumonias. An official American Thoracic Society/European Respiratory Society statement: Update of the international multidisciplinary classification of the idiopathic interstitial pneumonias. Am J Respir Crit Care Med. 2013;188:733-48.

23. Raghu G, Rochwerg B, Zhang Y, et al. American Thoracic Society; EuropeanRespiratory society; Japanese respiratory society; Latin American thoracic association. An official ATS/ERS/JRS/ALAT clinical practice guideline: treatment of idiopathic pulmonary fibrosis. An update of the 2011 clinical practice guideline. Am J Respir Crit Care Med. 2015;192:e3-19.

24. Hyzy R, Huang S, Myers J, Flaherty K, Martinez F. Acute exacerbation of idiopathic pulmonary fibrosis. Chest. 2007;132:1652-8.

25. Park IN, Kim DS, Shim TS, Lim CM, Lee SD, Koh Y, Kim WS, Kim WD, Jang SJ, Colby TV. Acute exacerbation of interstitial pneumonia other than idiopathic pulmonary fibrosis. Chest. 2007;132:214-20.

26. Knaus WA, Draper EA, Wagner DP, Zimmerman JE. APACHE II: a severity of disease classification system. Crit Care Med. 1985;13:818-29.

27. Sato T, Takeno M, Honma K, Yamauchi H, Saito $Y$, Sasaki T, Morikubo H, Nagashima Y, Takagi S, Yamanaka K, Kaneko T, Ishigatsubo Y. Heme oxygenase-1, a potential biomarker of chronic silicosis, attenuates silicainduced lung injury. Am J Respir Crit Care Med. 2006;174:906-14.

28. Nakashima K, Sato T, Shigemori S, Shimosato T, Shinkai M, Kaneko T. Regulatory role of heme oxygenase- 1 in silica-induced lung injury. Respir Res. 2018:19:144.

29. Lakari E, Pylkäs P, Pietarinen-Runtti $P$, Pääkkö P, Soini Y, Kinnula VL. Expression and regulation of hemeoxygenase 1 in healthy human lung and interstitial lung disorders. Hum Pathol. 2001;32:1257-63.

30. Kao KC, Hu HC, Chang CH, Hung CY, Chiu LC, Li SH, Lin SW, Chuang LP, Wang CW, Li LF, Chen NH, Yang CT, Huang CC, Tsai YH. Diffuse alveolar damage associated mortality in selected acute respiratory distress syndrome patients with open lung biopsy. Crit Care. 2015;19:228.

31. Usui Y, Kaga A, Sakai F, Shiono A, Komiyama K, Hagiwara K, Kanazawa M. A cohort study of mortality predictors in patients with acute exacerbation of chronic fibrosing interstitial pneumonia. BMJ Open. 2013;3:e002971.

32. Pereira MLM, Marinho CRF, Epiphanio S. Could Heme Oxygenase-1 be a new target for therapeutic intervention in malaria-associated acute lung injury/acute respiratory distress syndrome? Front Cell Infect Microbiol. 2018; 8:161.

33. DeRemee RA. Serum lactic dehydrogenase activity and diffuse interstitial pneumonitis. JAMA. 1968;204:1193-5.

34. Hara Y, Shinkai M, Kanoh S, Fujikura Y, Rubin BK, Kawana A, Kaneko T. Arterial carboxyhemoglobin measurement is useful for evaluating pulmonary inflammation in subjects with interstitial lung disease. Intern Med. 2017:56:621-6.

35. Kanoh S, Kobayashi H, Motoyoshi K. Exhaled ethane: an in vivo biomarker of lipid peroxidation in interstitial lung diseases. Chest. 2005;128:2387-92.

36. Alam J, Cook JL. How many transcription factors does it take to turn on the heme oxygenase-1 gene? Am J Respir Cell Mol Biol. 2007;36:166-74.

37. Rhen T, Cidlowski JA. Antiinflammatory action of glucocorticoids--new mechanisms for old drugs. N Engl J Med. 2005;353:1711-23.

38. Steinberg KP, Hudson LD, Goodman RB, Hough CL, Lanken PN, Hyzy R, Thompson BT, Ancukiewicz M, National Heart, Lung, and Blood Institute acute respiratory distress syndrome (ARDS) clinical trials network. Efficacy 
and safety of corticosteroids for persistent acute respiratory distress syndrome. N Engl J Med. 2006;354:1671-84.

39. Juarez MM, Chan AL, Norris AG, Morrissey BM, Albertson TE. Acute exacerbation of idiopathic pulmonary fibrosis-a review of current and novel pharmacotherapies. J Thorac Dis. 2015;7:499-519.

40. Majer AD, Fasanello VJ, Tindle K, Frenz BJ, Ziur AD, Fischer CP, Fletcher KL, Seecof OM, Gronsky S, Vassallo BG, Reed WL, Paitz RT, Stier A, Haussmann MF. Is there an oxidative cost of acute stress? Characterization, implication of glucocorticoids and modulation by prior stress experience. Proc Biol Sci. 2019;286:20191698.

41. Almeida M, Han L, Ambrogini E, Weinstein RS, Manolagas SC. Glucocorticoids and tumor necrosis factor a increase oxidative stress and suppress Wht protein signaling in osteoblasts. J Biol Chem. 2011;286:44326-35.

42. Zhang Q, Ju Y, Ma Y, Wang T. N-acetylcysteine improves oxidative stress and inflammatory response in patients with community acquired pneumonia: A randomized controlled trial. Medicine. (Baltimore). 2018;97: e13087.

43. Kishaba T, Tamaki H, Shimaoka Y, Fukuyama H, Yamashiro S. Staging of acute exacerbation in patients with idiopathic pulmonary fibrosis. Lung. 2014;192:141-9.

44. Murohashi K, Hara Y, Saigusa Y, Kobayashi N, Sato T, Yamamoto M, Kudo M, Kaneko T. Clinical significance of Charlson comorbidity index as a prognostic parameter for patients with acute or subacute idiopathic interstitial pneumonias and acute exacerbation of collagen vascular diseases-related interstitial pneumonia. J Thorac Dis. 2019;11:2448-57.

\section{Publisher's Note}

Springer Nature remains neutral with regard to jurisdictional claims in published maps and institutional affiliations.

Ready to submit your research? Choose BMC and benefit from:

- fast, convenient online submission

- thorough peer review by experienced researchers in your field

- rapid publication on acceptance

- support for research data, including large and complex data types

- gold Open Access which fosters wider collaboration and increased citations

- maximum visibility for your research: over $100 \mathrm{M}$ website views per year

At BMC, research is always in progress.

Learn more biomedcentral.com/submissions 